\title{
A Policy Framework for Social Entrepreneurship in India
}

\author{
Mir Shahid Satar \\ (Department of Management Jamia Hamdard University New Delhi, India)
}

\begin{abstract}
Although, the emerging literature on social entrepreneurship (S-ENT) is riddled with theoretical inconsistencies, definitions controversies \& framework contestations, the evidences supporting the role of $S$ ENT in fostering the socio-economic development of nations are evolving continuously. However, the policies concerning the creation \& management of social enterprises are yet to be crafted in majority of the countries including India. This paper draws on the prevailing state of relevant policies \& recent S-ENT policy developments within India. The paper attempts to analyze the system necessities \& develops a conceptual framework of S-ENT policy in India. The paper finds that there is significant increase in the policy development efforts from Governments of certain developed countries. However, there are little or no concerns for S-ENT policy framework in majority of developing countries including India. Hence, the paper lays the foundation for development of the policy framework for S-ENT in India.
\end{abstract}

Keywords: Social Enterprise; Social Entrepreneurship; Policy Framework; Government; India

\section{Introduction}

The Entrepreneurship Policy has emerged as the focus of public policies in the majority of the countries in the recent past. There is an increasing number of Governments paying attention to entrepreneurship policy and are subsequently implementing strategies in order to enhance the level of entrepreneurial activity in their nations (Minniti, 2008). The research analysing the importance of entrepreneurship in economic growth is increasing across nations (Audretsch and Thurik, 2001a; Global Entrepreneurship Monitor, 2002; Reynolds at al., 1999a; Wennekers and Thurik, 1999). Even in the Indian context, studies have shown the positive impact of entrepreneurship index on per capita income (Awasthi et el., 2006) and have explicitly shown the scope of the knowledge-based entrepreneurial economy in the developing countries like India (Figini and Santarelli, 2006) . Further, a significant amount of efforts is currently being done to recommend what needs to be done in order to enhance the level of entrepreneurial activity within a country (European Commission, 1998; Verheul et. el., 2001, Nisa, 2013).

The recent time has witnessed a gradual shift in policy orientation of India with innovation and entrepreneurship promotion strategies occupying top priority in the Government's strategic planning process. There have been considerable Governmental strategic initiatives for promoting knowledge-based entrepreneurship as a tool for generating employment, supporting social businesses in particular and enhancing the global competitiveness of the small firms. E-g; New initiatives under 'Make in India ' policy (2014) 'ministry formation for skill development and entrepreneurship-2014', 'National policy for skill development and entrepreneurship' (2015) etc. This response has largely been in recognition of changing social and economic environment in the country, rapid technological advancements, rise of a knowledge based economy, need for inclusive growth, state inefficiencies in service deliveries, overwhelming share of informal/un-organized sector, resource limitations, global race for competitiveness, expansion of service sector, private sector spread, and so on. Furthermore, there has been an increased recognition of the role of entrepreneurship and innovation in employment generation, economic wealth creation, social and economic renewal, addressing inequality, and a range of other social and economic problems (Awasthi et. el., 2006; Carree and Thuruk, 2003; GEM, 2002). Thus, depending upon their perception of the role of entrepreneurship, the Government of India (GOI) ${ }^{1}$ is at different stages of supporting the development of entrepreneurship policies.

India is regarded as the hot-bed for the entrepreneurial activities carrying the seeds of social concern. Here, we have the field of social entrepreneurship (S-ENT) ${ }^{2}$ emerging as a potent tool for solving social problems in an entrepreneurial way. While there is a mounting number of social issues' prevailing in Indian markets, they simultaneously offer some powerful opportunities for S-ENT efforts to spur up.

S-ENT in India albeit in its nascent stage is gradually receiving a thrust nowadays. With the Government and the traditional economic means of planning, funding and provisions of services such as health, education, and social welfare etc. tuning too inefficient, new attitudes to social problems and new expectations of citizens towards sustainable development are rightly arising now. However, while on one end of the continuum, we have the field of S-ENT as an exceptional opportunity to explore, analyze, challenge and rethink the central concepts and assumptions related to the social and economic development, on the other end we have a poorly defined and unstructured S-ENT sector in India (Satar, 2015; Satar \& John, 2016). The Indian social 
enterprises (SEs) ${ }^{3}$ lack sectorial recognition and there is no uniform understanding of the concept of S-ENT in India till date. As such there is an absence of regulatory framework or any formal recognition system for SEs in India. The policies pertinent to the creation, sustenance, and management of SEs are yet to be crafted.

The purpose of the present paper is to construct a conceptual policy framework for S-ENT in India and thus to further stimulate research in this direction.

\section{Literature Review}

The S-ENT in common parlance refers to entrepreneurial activity with an embedded social purpose. Thus, S-ENT mainly stands for endeavors which primarily focus on social value creation and hence social mission remains central to every S-ENT activity.

S-ENT as a social problem-solving endeavor is emerging as a socially innovative business model for the required social transformation and change in the whole world. Considering its assumed potential for solving the social problems, the arena of S-ENT is receiving significant attention from both scholars as well as practitioners globally (see Peredo and McLean, 2006; Thompson et. el., 2000) and this interest in social enterprise (SE) ${ }^{4}$ continues to grow (Nicholls, 2008). The S-ENT, as a phenomenon is eliciting profound interest among the elites as well. However, S-ENT philosophy is still considered to be in its budding phase (Short et. el., 2009). The field is having fragmented literature and there is lack of consensus regarding the framework and theory of S-ENT (Certo and Miller, 2008; Hill et. el., 2010; Mair and Marti, 2006; Short et. el., 2009). As such, S-ENT is eliciting a significant academic curiosity across array of fields like management, public policy, entrepreneurship, sociology and many others (Austin et. el., 2006; Certo and Miller, 2008).

\section{The nature of social enterprises and need for policy development- Global Perspective}

Social entrepreneurs have been found to operate in diverse sectors (health, education, agriculture, energy, environment etc.). They deliver different kinds of products or services especially targeting the marginalized or poor sections of the society. Such market segments of SEs have majorly been identified as least lucrative in anticipation of poor returns and the Government has turned too inefficient in serving such sections. Thus, on account of uncertainty associated with the returns of social entrepreneurial investment, the S-ENT efforts are often deemed as riskier than the traditional businesses. At times, they have to create both value chains and market access and even the new markets as well. Alternatively, they are engaged in tackling some of the toughest challenges in the world (Dees, 1994) as they have to reach far more people with far less money. While doing so, they adapt different models of business operations, processes and organizational structures. Such business models of SEs can lie across the continuum of for-profit to not-for-profit ventures. The former can fund its operations through private sector income while as the later depend on grants, charities and other sorts of financial aids. Yet, other forms of SEs have been identified as adopting a hybrid model. They combine nonprofit activities with certain profit making areas. Nevertheless, the profit doesn't constitute the main purpose of such ventures (Bornstein, 2004; Dees, 1994; OECD, 1999; SEL, 2001b).

SEs have majorly been identified as resource scarce (Young, 2006), having a wide democratic stakeholder base (Smallbone et. el., 2001) with "non-distribution constraint" (Hansmann, 1980), pursuing dual objectives (social and economic) and unlike traditional businesses signify a bottom-up approach of development. These characteristics, although unique poses distinct and substantial challenges in the strategic management of such enterprises. While access to resources has been recognized as critical for SEs, they confront more challenges in accessing the resources than their commercial counterparts (Austin et. el., 2006) and have been projected as competing for resources with their commercial counterparts in future (Johnson,2000). Therefore, SEs can't operate in isolation. They depend on different kinds of support actors like entrepreneurs, civil society, academicians, state actors, funders or incubators etc. for their establishment and subsequent management. SEs require different kinds of support depending on their core activity, the stage of development as well as their internal capacities. Hence, putting in place a conducive policy environment for SEs turns to be critical for enabling SEs to realize their potential of not only creating jobs but also of addressing a range of social and economic issues for a more inclusive and cohesive growth of communities.

Globally, the businesses, Governments, $\mathrm{NGO}(\mathrm{s})$ and other multilateral donor agencies are increasingly recognizing that their support of social entrepreneurial efforts can fetch significant benefits to society at large. However, the current research and policy debates have not yet fully matured to offer conclusive evidences regarding optimal forms of involvement, system components and necessities and other policy commendations (Nielsen and Carranza, 2010).

\section{Social enterprise landscape in India}

The entrepreneurial activities or ventures carrying seeds of social concern are being established and managed in diverse geographical contexts and organizational forms across India. The Indian SEs lack sectorial recognition and there is no uniform understanding of the concept of S-ENT in India till date. As such there is an 
absence of regulatory framework or any formal recognition system for SEs in India. The Indian social entrepreneurs are majorly deprived of formal sectorial benefits like tax breaks or incentives etc.

There is dearth of even definitions and a wide diversity prevailing among the organisational forms adopted by SEs within India (Satar \& John, 2016). The multidimensional nature of social ventures, as well as the variegated nature of social problem solving in India, poses substantial challenges with regard to defining and delimiting the boundaries of SE operation. The Indian SEs have partially been receiving the attention of researchers and policy makers. Even very little is known about their management and organization and we do not have a comprehensive picture of their processes till date. The policies pertinent to the creation, sustenance, and management of SEs are yet to be crafted. Surprisingly, a majority of the Indian social entrepreneurial efforts stay with meager results. They go unorganized and unnoticed by dint of poor support and recognition they are getting from multiple agents. They stay with financial difficulty on a self-employed scale.

\section{The prevailing state of policy development for social entrepreneurship}

SEs have acquired tremendous thrust in the policy debates of many European and non-European countries. The European started with many social entrepreneurial initiatives, like the recent "Social Business Initiative" etc. in an attempt to provide a legal identification to European SEs. This served as an important breakthrough for policy makers and other stakeholders of socially inclined businesses in the European region.

S-ENT movement is catching impetus within Indian markets too. The GOI is prosperous of playing a critical role in the development of SEs in India. This heightened interest for policy treatment of entrepreneurship is manifested in the form of Government's involvement in shaping the policies concerning the management of Micro, Small, and Medium Enterprises (MSMEs) within India. Although, it doesn't affect the SE sector directly but it duly impact the functioning of regional SEs. There have been certain national policies (in the form of public-private partnerships) for fostering social innovation like 'India Inclusive Innovation Fund-IIIF' run by the 'National Innovation Council'. The 'National Innovation Council' has gone a step ahead by establishing 'State Innovation Councils' (e-g; Bihar Innovation Forum sponsored by Bihar Government in collaboration with World Bank). Furthermore, there are certain councils like 'Sectorial Innovation Councils' which although not specifically focused on social innovation but they do support the innovations meant to address any important national development issue. The role of SEs and innovation has also been emphasized in the Government's twelve5th Five Year Plan (2012/ 2017). Thus, the firms adopting these themes receive top priorities in the national policy agenda. Thus, GOI, as well as international policy maker's active in India, are keen to develop these enterprises as an integral part of solution to the India's developmental challenges. Therefore, the discussions pertaining to driving innovation within MSME and growing social businesses are entering into the policy thrust (GIZ, 2012). Under this agenda, MSME have been recognized as priority lending sector. The program will enable the eligible enterprises to avail capital through equity, Government grants and subsidized loans etc. Since, majority of for-profit SEs in India fall into this categorization (initial outlay below \$2 million; ADB report, 2012), they will thus stand benefited from this policy.

The policy emphasis for S-ENT is further manifested in the form of many recent policy debates. Like for e-g; the recent "National Policy for Skill Development and Entrepreneurship (2015)" as well as the formation of new "Ministry of Skill development and Entrepreneurship" (Planning Commission, 2013). While striving for achieving the global competitiveness through national skill development mission, the proposed policy carries certain agendas to foster S-ENT also. The policy strives to promote and encourage commercialization of grass-root innovation through collaboration and integration with pertinent groups of existing organisations (E-hubs) like technological innovation hubs, National Innovation Foundation, research ecosystem within the nation etc. The policy agenda includes encouraging and starting the courses on S-ENT in higher education, funding schemes under social venture fund to extend credit to S-ENT, promoting and strengthening patent regarding innovative entrepreneurial ideas etc. However, these policy objectives are devoid of a holistic framework and don't cover all elements of a systemic S-ENT ecosystem.

Nevertheless, the policy marks an important breakthrough for the policy makers and other stakeholders of entrepreneurship in India. Moreover, it symbolizes an important break away from the earlier entrepreneurship development approaches within India. Previously, entrepreneurship and skill development missions were disseminated across different ministries and departments within the country (previously entrusted to MSME ministry and national skill development agencies etc.). Previous policies like "MSME Policy", "Competition Policy”, "Manufacturing Policy", "Science and Technology Policy”, "Industrial Policy", "National Design Policy", "Industrial Policy Resolution (IPR-1948, 1956, 1977, 1980 and 1990) etc. touch upon and do carry some indirect implications for entrepreneurship promotion. However, the plethora of such policies was more or less scattered, disjoint, without strategic content and having fragmented entrepreneurship focus. Therefore, after recognizing the role of skilling, training and entrepreneurship for greater inclusive growth, employment and economic sustainability, the immediate mandate of separate ministry is undertaken for the first time by GOI (2014). The proposed policy signifies a deviation in its approach as compared to previous policies. Unlike 
traditional policies which had an 'enterprise focus', the present policy carries an 'individual' focus to drive motivation, awareness, networking, skills and opportunity with the individuals with the expectation of fostering an entrepreneurship movement within the country.

\section{Existing legal framework for social enterprises in India}

Unlike many other countries, SEs in India have limited options in terms of legal structures they can adopt. Typically, SEs in India can take either of the following legal forms:

- Non-profits- or Charitable Organizations- can register themselves under the Indian Trusts Act (1882); section 25 of Companies Act (1956); State Society registration. E-g "Digital Green"; "Teach for India"; "Akshaya Patra" etc.

- For-profits- Can adopt either of the structure; sole proprietorship, partnership, limited liability partnership, private firm and co-operative. E-g "Vaatsalya Healthcare";" "dLight" etc.

- Hybrid structures- incorporating features of both the above structures simultaneously. E-g; "Head Held High Foundation"; “Fractal Foundation”' Etc.

While each of the structures offers certain advantages, they are not free from limitations as well. For e$\mathrm{g}$ while the traditional non-profit organisational model enables the firms to get tax and foreign donation benefits under the Income Tax Act (1961) and Foreign Contribution Regulation Act (2010) respectively, the legal structure simultaneously makes them to raise funds continuously. Therefore, they find hard to hire/retain top talents or invest in state of the art infrastructure and technology. As a consequence, non-profits/ NGO's in India are increasingly being found following the trend of conversion to for-profit mode or adopting some profit generating avenues partially as a measure for self-sustainability. For example; microfinance institutions like 'SKS' and 'Spandana' were first created as non-profit models and now transformed into for-profits (Asian Development Bank, ADB study report, 2012).

In India, SEs are operative in a wide range of activities, in different sectors. A review of these sectors was presented in the ADB report, 2012. See table1.

Table 1: Key social enterprise investment sectors in India

\begin{tabular}{|l|l|l|}
\hline Education & Health & Agriculture \\
\hline Affordable Housing & Energy & Livelihood Promotion \\
\hline Water and Sanitation & Financial Inclusion & \\
\hline
\end{tabular}

Source: ADB Report, 2012

In absence of a legal framework in a country, SEs may find it hard to get their dual (social and economic activities) recognized or may be subjected to inappropriate legal and regulatory frameworks. The range of regulatory challenges that restrict different players in the SE ecosystem may include for e-g; the lack of legal structure, equity investment regulations, restrictions on blended capital and restrictive laws on foreign capital flow etc. (GIZ, 2012).

A consolidated foundation for SEs in India would be met by laying an appropriate legal framework, craved to suit the contextual needs and specificities of Indian SE culture. Such a legal framework at national and state levels would be useful in many ways including; the ways to create a national social entrepreneurial milieu especially in a context where one doesn't exist; in clarifying the SE definition and missions; in opening up opportunities for fiscal incentives/relief; in providing access to public resources and support; in developing measures for social impact evaluation etc. depending upon their core activity, the stage of development as well as their internal capacities.

\section{Existing institutional support to entrepreneurship promotion in India}

GOI through various institutions (especially financial e-g; SIDBI, NABARD; capacity building through academic institutions e-g; Entrepreneurship Development Institutions- EDI's) strive to empower entrepreneurship by shaping the enabling policies, programs and attitudes towards MSME's and civil society. However, it has a role although small in supporting the functioning of regional SEs. Further, a certain number of institutions (e-g; Indian industry bodies, CII) have emerged as enabling the SE sector through various activities related to S-ENT.

Further, there is a significant increase in the engagement of different stakeholders of the social business landscape in India. In this regard, a growing number of new initiatives from the private players have taken shape or on the agenda of several multi-lateral stakeholders of SE ecosystem within India (GIZ, 2012). As a consequence, there has been an increase in interest of Indian Central and State Governments in engaging the private sector in addressing some of the national developmental issues. For e-g., Engagement of the private sector in the delivery of emergency health services in many states under public-private-partnership (PPP) model etc. Moreover, an increasing number of 'impact investors' with an interest in supporting businesses with social 
and environmental impacts are entering the Indian SE landscape e-g; DFID-SIDBI Partnership, The Millennium Alliance - USAID and FICCI, GIZ Small and Growing Social Businesses support (ADB report, 2012).

As a response, there has been a substantial increase in the interest of not just the Government and impact investors but also donor agencies, business incubators and other S-ENT facilitators as well. While for e-g the financial support has been identified as the major hurdle, the Indian SEs face in the way of their progress (Allen et. el., 2012), the Government here can play an important role by supplying the "impactful" capital or by encouraging the investment by those interested in SE returns. In this regard, a recent innovative move of 'Securities and Exchange Board of India (SEBI) in floating a national policy for separately recognizing and regulating the "Social Venture Funds" within India. (In 2013 "InCube Connect Fund" Gujarat, was recently approved by SEBI under SEBI (AIF), Regulations, 2012 as India's first social venture fund). Such policy interventions are hopeful to greatly impact the SE development within the nation.

\section{Social entrepreneurship policy- as a broad based growth enabler}

Over the past two decades, S-ENT has been acknowledged as an important socially good endeavor by virtue of its potential in fostering an inclusive growth for the greater benefit to the communities. This ensuing belief about S-ENT grew as a response to some tangible outcomes it offers to the society which may include for example facilities like efficient delivery of public services, welfare benefits, making not-for-profit organizations self-resilient etc. The modified and redesigned role of SEs is now attracting significant attention at the policy levels, primarily due to their assumed potential to contribute to social, economic and environmental regeneration or a combination of these.

Unlike the traditional top-down approach of development, SEs represent a paradigm shift by leading a renewed bottom-up approach of development. Obviously, their beneficiaries are constituted of poor and the marginalized people, the choices of whom become the central reference points in the SEs planning and decision making. One of the pertinent goals of the S-ENT sector is the creation of social ventures as well as the new SE culture specifically oriented at the inclusion of marginalized groups through active participation in it. Thus, it serves as a promising response to the much prevailing disproportions between rich and poor.

S-ENT offers an exceptional opportunity to create businesses that are economically viable, scalable and job creating (Harding R, 2004). The role of SEs in employment generation is globally acknowledged (Noya and Clarence, 2007; OECD, 1999). Even, there are growing numbers of studies confirming the increasing share of jobs offered by SE sector. For instance, within the European Union, the number of jobs in the S-ENT sector increased from 11 million to 14 million during 2002-210 (CIRIEC, 2012). The jobs in SE sector present some distinguishing features such as triple bottom line orientation (Leviner et. el., 2007), local/regional development (Ireland et. el., 2001) or empowerment (ECOTEC 2001), inclusion of destitute communities (Karnani, 2007) or the development of remote rural or distressed urban areas (e-g., social co-operatives in Italy and Poland), where there is little or no propensity of wealth creation (Bornstein, 2004; OECD, 1999).

SEs are being identified as representing socially innovative and sustainable model of future development for the whole world (Leadbeater, 1997; Oatley, 1999). This potential of SEs emerges not only for its job-creating capacity but as their pivotal role in social capacity building, responding to unmet needs, creating new forms of work (Amin, 2005), promoting local development, fostering integration, defining new goods and services, consolidating local assets, improving attractiveness of an industry and locality (ECOTEC, 2001) and also fighting a range of other social issues (Alvord et. el., 2004; Dees and Elias, 1998; Peredo and McLean, $2006)$ as well as furthering more inclusive growth (OECD, 2013).

The endeavor of social problem solving is arduous and challenge filled and often demands fundamental alterations in the economic, political and social systems that underpin current stable states (Alvord et. el., 2004). Here, working with and promoting SE sector provides an exceptional opportunity for short and long term gains for public budgets through reduced public expenditures and enhanced tax revenues as compared with the other methods of social problem solving. Thus, SEs represent the most effective strategies (as compared to either private or public) for fulfilling the public goals as SEs possess strong local roots and knowledge about the social issues/missions. The Government can work as a strategic partner to SE sector in addressing the intractable social problems. However, the intersection of policy and S-ENT field has to be established on some sound governing mechanisms. In this regard, there has been recent evidence from UK Government's 'social impact bond'. The 'social impact bond' utilized by "Social Finance- a UK based firm" depicts how Government can serve as a strategic partner in utilizing private investment for the social issues.

Further, supporting the S-ENT sector as a public policy domain would enable the Government to meet the employment needs as well as other economic and social challenges in a more efficient, effective and sustainable way. The policy support for creation and management of SEs would improve the Government's public spending as well as will lessen their dependence on the traditional public or private sector (OECD, 2013). The above policy formulation endeavor will demand an inclusive participation by the Government as well as the social economic sector itself (Mendell et. el., 2009). The evidences in support of benefits which accrue to SEs 
from public policies are rising globally. For instance; it was found in the analysis of ten SEs operating in different sectors within France that the public money spent for the support of these SEs actually enhanced the efficiency of public spending (Ashoka/McKinsey and Company, 2012). Alternatively, it comparatively represents a more efficient way of utilizing the public resources. Thus, the public spending/support for SEs emerges as a systematic cost-effective strategy as well as a policy that would enable the Government to meet the needs of deprived or marginalized sections of the society. In a way, the policy support would favor the social cohesion and more inclusive growth within national economy.

The contribution of SEs can be increased by enabling Government policies at the local, state as well as at national level. The focus of these policies should be on SE development process through: encouraging, incentivizing and supporting social entrepreneurs as well as fostering social innovation within the SE sector, providing an enabling environment in which S-ENT can flourish, improve the legal status, fiscal and regulatory frameworks of SEs, provide contexts through which the support can flow, improve financing, business development, market access, services, training as well as supporting further research in the sector. The focal point with regard to policy development should be that the Government shall adopt a systemic approach to capacity building and scale up of SEs to contribute more effectively to sustainable growth and development of the economy.

\section{Research Gap}

An extant review of the existing research on S-ENT reveals the lack of a comprehensive policy framework for understanding the complexities of the phenomenon and its broader determinants. Although, SENT has been regarded as a socially good endeavor, it requires definition and thorough elaborations. There are no clear cut guidelines of how to enhance and regulate the S-ENT activities within the nation. Even, there is little or no policy consideration for S-ENT ecosystem in the Indian economy. The Government is short of a reliable research base which can be referred for making key policy decisions in the area.

Amidst the presence of abundant theoretical controversies and overlapping definitions, the researcher attempts to explore this nascent yet potential area of policy development for S-ENT within the nation. Looking into the present ill-developed nature of the S-ENT concept, it seems too early to make a shift to the policy framework development. However, the researcher makes a modest attempt to explore this nascent area of policy development for S-ENT, which has received diminutive attention up to now. The paper couldn't represent a complete description of the entire happenings in Indian S-ENT landscape. However, it is a modest attempt to provide an overview of the national scene, describe major programs and measures of the national institutions and other policy agendas of Government and also provide a link of how these could be coordinated to bring forward a cohesive framework of S-ENT operation in the economy.

\section{Objectives}

The paper seeks to explore the policy areas concerning the moderately contested field of S-ENT. The paper responds to the recent S-ENT policy development of India and attempts to addresses the need for policy development for this sector.

The following constitutes the main objectives of the paper:

i. To explore the policy development of S-ENT in India.

ii To construct a conceptual framework for social entrepreneurship policy in India.

This paper is based on the published documentary work of others. The extensive literature survey concerning the policy development of S-ENT and allied areas was carried out. Moreover, the official websites of relevant global organisations and Governments were accessed. The paper lays the nascent foundation for understanding how the different actors of S-ENT ecosystem can come forward for constructive S-ENT policy development in India.

\section{Methodology Approach}

The researcher analyzed various existing entrepreneurship models and examined their implications for the social entrepreneurial context. From the existing entrepreneurship models and thorough investigation of Indian social S-ENT landscape and the recent S-ENT policy concerns of GOI, the researcher is making a framework of S-ENT policy.

There are several existing models of entrepreneurship policy as for e-g, the study conducted by Lundstrom and Stevenson (2001) strived to answer the query of "what should be done to produce the higher level of entrepreneurial activity'. The study is actually based on the description of Government actions towards entrepreneurship in several countries. However, there is little knowledge of how an effective entrepreneurship policy is constructed. The study focused on analysing different policy measures and their objectives and rationale. After a comprehensive research of entrepreneurship policy in several economies, Lundstrom and 
Stevenson found that entrepreneurship policy is different from country to other. The researchers came up with a framework of entrepreneurship policy which depicts the relationship between the determining variables (population growth, level of economic development, growth in per capita GDP, growth in immigration rate etc.) and entrepreneurship activities.

Further, Lundstrom and Stevenson (2005) stated that the desired entrepreneurship policy outcome means an increased level of entrepreneurial activity in an economy. If entrepreneurship is a system, then the role of the Government and institutions is to foster environment that will produce a continuous supply of new entrepreneurs as well as to offer conditions that will enable them to start and grow enterprises.

Lundstrom and Stevenson (2005), defined entrepreneurship policy for the first time as the policy measures taken to stimulate entrepreneurship at different stages (pre-start, start-up and early post start-up phases) of an entrepreneurial process. Therefore, such measures intend to address the areas of motivation, opportunity and skills with the primary objective of encouraging more people to consider entrepreneurship to move into the nascent stage and proceed into start-up and early phases of a business. Thus, in a way, the definitions linked policy to purpose or goal oriented actions.

The research conducted by Dutz et. el., (2000) states that protecting commercial freedom; property rights etc. and fostering opportunities for grassroots entrepreneurship are two essential policy measures for low income countries. The measures emphasized the improved access to vital business services and other local inputs through ensuring an active supply-side competition policy.

Policy measures are known to influence the level of entrepreneurship (Storey, 1994, 1999). Verheul et. el., (2001) in their research described how and in what stage that government can make interventions. The determinants of entrepreneurship can be classified according to different approaches as for example the disciplinary approach, the level of analysis, the discrimination between demand and supply factors etc. As per the level of analysis, there are three levels i-e. micro, meso and macro with different levels of focus at each level (Verheul et. el., 2001).

In the similar vein, the research conducted by Wennekers and Thurik (1999) divided the entrepreneurship policy category into two kinds of interventions. The first level of intervention seeks to promote the creation of technology-based firms in selected industries and the second level of the intervention aimed to promote the development of newly created firms, regardless of the sector in which the firm is operating. Their research suggested the role of Government in stimulating entrepreneurship culture or social capital and emphasized the need for enhancing business skills and creation of an appropriate institutional framework at the country level.

Further, the entrepreneurship process model introduced by GEM team focused on the conditions that shaped entrepreneurship, and its direct economic impacts. The GEM entrepreneurship framework described the framework conditions for e-g. the elements of environment, opportunities, motivation and capacity to shift the focus from conventional model to entrepreneurial model (Reynolds et. el., 1999).

Research conducted by Kim et. el., (2010) examined the effects of finance, labour and tax policy and other factors on entrepreneurial activity. The entrepreneurship policy is classified by two major dimensions i-e, the unit of analysis and level of analysis. The unit of analysis focus on the relation between individual characteristics like personality traits, motivation, educational background etc. and entrepreneurship outcome and the level of analysis can be the regional or country wide focus of macro factors of entrepreneurship outcome.

Dana (1992) developed a framework of public policy on entrepreneurship by examining the role of public policy in affecting the entrepreneurship environment in six different economies. The study examined and classified the six different model based on the level of Government intervention and the affinity for entrepreneurship. The study found that the social value as attached to entrepreneurship and the level of Government intervention are two important factors affecting each other and suggests that a Government which values entrepreneurship, coupled with laissez-faire- style policy of Government can serve as an assets in an economy. Thus, in less-developed economies, where there is low social value attached to entrepreneurship, the focus should be on entrepreneurship development programs. Thus the policies which can reach, educate and activate people at the local level are a must advocate (Dana, 1992)

Dana (1995) in a further study examined and classified the policy styles of thirteen Caribbean economies based upon the nine theoretical positions in an integrated framework. The study revealed that the economies with high levels of Government intervention and higher economic regulation coupled with lower entrepreneurial values had comparatively lower GDP's. While on the other hand, the economies with higher entrepreneurial values, minimum regulations and intervention had highest per capita GDP (Dana, 1995).

\section{Conceptual Framework of Social Entrepreneurship Policy}

S-ENT is projected or seen as sharing much in common with business management and entrepreneurship (Granados et. el., 2011; Satar et. el., 2016). As such, the different approaches of management domain find high appropriateness for application, explanation and further expansion of this field (Satar and 
John, 2016). In light of above, it would be appropriate to study and analyse the dimensions of entrepreneurship policy and strategies for subsequent policy framework development of S-ENT.

Secondly, S-ENT is still regarded as a contested concept, meaning different things to different people (Dees, 1998; Mair and Marti , 2006). Over the time, different researchers have attempted to view the S-ENT through varied contextual lenses and methods of analysis. However, for the purpose of framework development, the present study views the S-ENT in a process oriented context and contends that S-ENT is not merely what social entrepreneurs do; rather it is essentially a systemic process, activities, a social phenomenon that emerges within the broader social, economic and political context and involves a diverse and large number of actors.

Further, for the same purpose, S-ENT can appropriately be viewed in a system approach where social entrepreneurs, regional/state Governments, and other allied actors and institutions constitute an integral part of the overall S-ENT ecosystem. Here, the Government and other actors can play a critical role by influencing the S-ENT process in multiple ways (Storey, 1994; Verheul et. el., 2001).The scenario will demand the formulation of desired policy that will regulate, reinforce and promote the interactions between different system components as well as social entrepreneurial activities within the ecosystem. The outcome of the systemic process should ideally help in bringing in a new supply of potential social entrepreneurs while subsequently ensuring their success in establishing, managing and growing the social ventures. Therefore, the system necessitates the concern for the individual social entrepreneurial process from initial awareness of S-ENT option to early stage survival and growth of the SE.

\section{Proposed framework: description}

It is widely acknowledged that policy measures can influence the level of entrepreneurship (Storey, 1994) and the Government can make potential interventions in multiple ways (Verheul et. el., 2001). Further, the determining factors of entrepreneurship can be categorized as per the different approaches like the level of analysis, demand and supply factor discrimination, disciplinary approach etc. (ibid). As per the object of study, the level of analysis can be micro, meso and macro (ibid). The determinants of S-ENT levels can be conceptualized through considering the factors affecting the individual social entrepreneurial process from initial awareness of S-ENT option to early stage survival and later growth of the SE. Thus, the levels of S-ENT activity in an economy canwell be increased by ensuring the outperformance in these determinants through a holistic policy framework. 


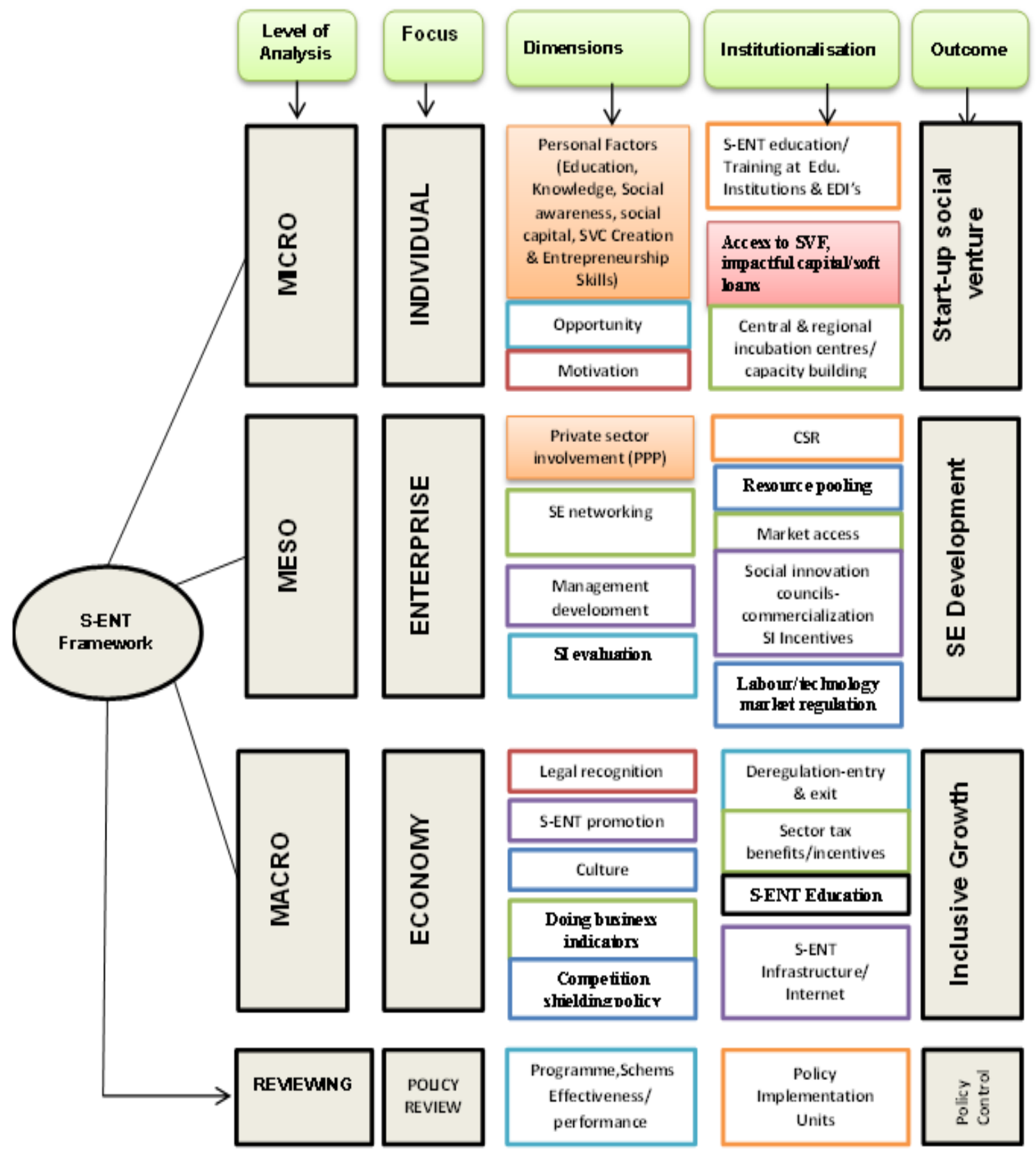

Source: Author's own creation

\section{Fig. 1: A conceptual policy framework for social entrepreneurship}

\{S-ENT=Social entrepreneurship; SE= Social Enterprise; CSR= Corporate Social Responsibility, SI=Social Impact; SVC= Social Value Creation; SVF= Social Venture Fund; EDI= Entrepreneurship Development Institutions; PPP= Public Private Partnership\}

\section{Social entrepreneurship policy: Government interventions}

\section{Policy intervention at micro level}

The micro level will have an individualistic focus where the determining factors of S-ENT levels will depend on the individuals (social entrepreneurs) decision making process, their motives for choosing S-ENT as career option, social values, family background, level of S-ENT awareness (Dana, 2000), personal factors such as their psychological traits like need for self-actualization, desire for independence and autonomy (Rotter, 1966), need for achievement (McClelland, 1961) or passion for solving social issues (social value creation orientation of the social entrepreneur), entrepreneurship orientation and past experience, role modeling, education level and relevant business skills/expertise etc. Stimulating social temper (of social issues) and the enhancing the ability of individuals to exploit these problems as business opportunities (commercialization) are 
critical interventions at this early stage of the process. Thus, building confidence and motivation within potential individuals constitutes a key policy thrust at this stage. Due to the presence of unique challenges in social business context (like duality of SE goals), the successful identification and exploitation of social business opportunities will thus demand not only the possession of general business skills (like creative problem solving, strategic thinking, persuading, negotiating, deciding under uncertainty etc.), but also a range of other social business skills that are specific to the social enterprise's focus (like networking, resourcefulness, passion for social causes, social value creation, social capital etc.).

Technical, industry-specific training is an important component in the creation of globally competitive firms (Kantis and Ishida, 2002). The policy measures at this stage would thus strive to obtain the above mentioned combination of skills through diverse social entrepreneurial education and training programs. Such programs can well be implemented through the already existing network of education, training and entrepreneurship research institutions within the country. However, due to the extreme diversity prevailing within Indian SE sector, the validity of a particular skill development initiative needs clarification.

Once the individuals have decided to venture into S-ENT, the focus at the micro level shall accordingly move to supporting the individual social entrepreneurs through providing multi-aspect support and services at pre-start and start-up phases of individual S-ENT process like start-up financing facilities which include for example better access to start-ups finance/soft loan/venture or angel capital, increasing 'impactful capital' 'social venture fund' 'business incubators' etc. Although the Government has been offering the start-up incentives and other support services, however, their success for social business start-ups needs clarifications. Further, the awareness and accessibility of these start-up incentives for regional/rural social entrepreneurs in India is a major policy challenge to address.

Thus, the policies at the micro level could be defined as the measures undertaken to stimulate S-ENT through providing multipronged assistance at the pre-start and early start-up phases of the individual S-ENT process. The goals of measures here would include making the process of S-ENT easier for potential individuals in order to remove their barriers/challenges and would build confidence and increase their morale in the social business venturing. In this way, an individual's ability to convert a social problem solving idea into action can be actualized.

\section{Policy intervention at meso level}

Here, the object of study is the SEs established out of the so called S-ENT process. The focus will be the sectors of industry (sector structure), outsourcing, networking and collaboration with multi-stakeholders like private sector engagement, better access to resources such as financial, technical, and organizational and other management support needed to grow. Market specific determinants of S-ENT such as social impact/profit opportunities as well as the opportunities for market entry and exit etc. also need to be considered as a policy thrust at meso level.

This stage of analysis becomes all the more important in India because businesses with social concern are being established and managed in diverse geographical contexts and organizational (informal/unregistered) forms (NGO's/MSME) across India. Although the Government has been providing support through diverse programs at the start ups, a major chunk of problems occurs after start-ups. Generally, a large number of small businesses at early start-up phase suffer a pertinent number of managerial issues and thus eventually fail. Therefore, it calls for multipronged policy interventions at this stage.

Further, SEs measure their performance not only in terms of economic progress but also through 'social impact'. Often times, they require the undertaking of some balanced acts through strategic reflection and analysis on the part of managers and stakeholders in attaining sustainable impact. In the pursuit of measuring the S-ENT, one of the greatest challenges identified so far is to find a means of measuring both the levels of social entrepreneurial activity and the impact that S-ENT fetches in terms of macro variables of job-creation, poverty reduction etc. (Harding R, 2004). Even the SE investors are increasingly becoming interested to know the worth of their investment in terms of the social impact the SE creates. The accountability of SEs towards its beneficiaries and other stakeholders in terms of reporting of social impact has doubled in the recent past. In this regard, devising a policy agenda for nation-wide evaluation of social impacts is of topical importance. Developing and applying some solid and sound metrics for key construct measurement of social value/social impact will not only address the above frustrating problem of social impact evaluation but will also help in identifying the key sectors with high social impact as well as will strengthen and improve the future research and development of the SE sector in India.

Often the researchers have emphasized for the unique combination of skills and experience in key members of SEs required to operate in a non-profit and commercial context. The literature proves that implementation of business professionalism would mandate a cultural shift from being value led only to becoming more market led (Conway, 2008) while still maintaining the organization's mission, a difficult if not impossible balancing act for some to follow (Burns, 2010; Seanor et. el., 2007). In this direction, policy 
measures for continuous training and development for social entrepreneurs and key staff of SEs demands a critical policy intervention. This will not only make them apt at handling social ventures but will also lessen the probability of possible mission drift in SEs.

Social entrepreneurs have been identified as tackling the problems that the Government has not been able to solve. In this context, the Government can typically play an effective role by successfully collaborating with SE sector. The Government can work as a strategic partner to SE sector in addressing the intractable social problems. However, the intersection of policy and SE field has to be established on some sound governing mechanisms. In this regard, there has been recent evidence from UK Government's 'social impact bond'. The 'social impact bond' utilized by "Social Finance- a UK based firm" depicts how Government can serve as a strategic partner in utilizing private investment for the social issues.

Some other S-ENT policy measures at meso level may include (but not limited to) the following:

- Stimulating grass root innovation as well as social innovation within corporate sector.

- $\quad$ Social enterprise networking through a national coordination body

- Simplifying the process of intellectual property rights.

- Labor market and tax regulation for social enterprise landscape.

- Fostering Technology transfer/commercialization.

- Periodic identification and analysis of sector specific critical success factors of SEs

\section{Policy intervention at macro level}

At the macro level, the object of study becomes the national economy and its regulation as a whole. This would include the policy thoughtfulness for a range of environmental factors like technological, economic, cultural and other regulatory factors favoring or hindering the S-ENT growth and movement within the nation. The policy interventions at macro level could be discussed under following heads:

i. The Government has a major control over 'doing business indicators' in an economy. As per 'World Bank' reports, such indicators include factors like "measures of regulations for starting a business, dealing with construction permits, getting electricity, registering property, accessing credit, protecting investors, paying taxes, trading across borders, enforcing contracts and resolving insolvency" (World Bank, 2013). While serving as business regulating parameters, such indicators predominantly determine the ease of establishing as well as running an enterprise within an economy. However, beyond regulation, they may also refer to other indirect measures which have great impact on businesses. Considering the nascent stage of S-ENT growth, the aforementioned indictors may not specifically focus on the SE sector. Further, in the context of SEs, there can be the possibility of indicators which may have been framed till yet. Meanwhile, in case of India specifically, a 'well-defined minimum role' for the Government seems to be most relevant. The rationale for the minimized role could be to ensure that the influence of the free market and individual selfinterest can be fully realized.

ii. As SEs would be competing with their commercial counterparts, some national protective measures/shields by national regulatory authorities could help to protect SEs from competitions from the well-established private sector. For the sake of scaling their social impacts and to pierce more national developmental areas, the authorities can regulate the SEs in order to promote fair competitions within them and provide them with access to pertinent markets.

iii. Further, the legal recognition of SEs is must advocate as far as policy framework of SEs is concerned. The formal recognition as a sector would help in clarifying the SE definition and missions; in opening up opportunities for fiscal incentives/relief; in providing access to public resources and support; in developing measures for social impact evaluation etc. depending upon their core activity, the stage of development as well as their internal capacities. This could be achieved through enactment of certain sector specific new acts or amendment of existing MSME acts.

At the macro level, the Government can engage itself by undertaking actions associated with the direct promotion of S-ENT within a region. At the macro level, the role of an enabling Government policy is critical in terms of creating and nurturing S-ENT culture and infrastructure. Thus, policies at the macro level can be defined as the activities undertaken to stimulate more social entrepreneurial behavior in a region. Such promotional measures could include activities like creating and disseminating information, knowledge, education and awareness as well as projecting S-ENT as alternative career/employment option. Internet/social media access may be regarded as an important S-ENT infrastructure variable in modern days and thus can be prioritized by policy measures.

The Government can play a critical role in empowering the potential for creating a national social entrepreneurial milieu especially in a context where one doesn't exist. Therefore, as a broad based enabler, the Government's role in supporting policy development for S-ENT cannot be overlooked. 


\section{Policy interventions- Reviewing level}

The policy can be implemented through various programs and Government interventions. The principle which the framework advocates is the regular evaluation of the proposed and existing policies/interventions on the S-ENT environment. The evaluation principle seeks to find how well the stated policy supports the fair treatment and engagement of all stakeholders, taking into account the wider interests of the S-ENT sector/communities under consideration. Thus, the principle strives for periodic evaluations of programs and interventions to uphold the adaptability of the institutional framework so as to early detect the new challenges and respond back rapidly. The objective of evaluation can well be institutionalized through making special provisions for S-ENT assessment in "Policy Implementation Unit" provisioned under the "National policy for skill development and entrepreneurship-2015".

\section{Conclusion And Future Research}

Since the policy development for S-ENT is at an embryonic stage, there have been little or no policy framework concerns for S-ENT across the globe. Although, there has been a significant increase in the efforts towards addressing the policy issues of S-ENT in many developed countries (US, UK), however, more remains to be done. Moreover, there have been little or no such concerns in majority of developing countries including India. While as the Governments in both developed and developing countries are now increasingly concerned about the role of S-ENT in addressing the pertinent social problems and achieving other sustainable development goals, the need for the development of constructive policy framework is tremendous. The present research thus is a modest attempt to enter into this nascent, yet challenging field of policy development within India.

The chief contribution of the paper is the conceptual model integrating the different components of the S-ENT system. The proposed framework can be divided as per level of analysis into micro, meso, macro and reviewing level. In a systematic manner, the outcome of the intervention is highlighted at each level of analysis with the prospectus of reaching at a comprehensive S-ENT process in an ecosystem. Thus, in line with the existing models of entrepreneurship, the current framework advocates the specific interventions of Government and other actors at the above four levels for the sake of promoting, regulating and ensuring an orderly growth of the social businesses in India. The framework attempted to integrate a seemingly fragmented discourse on entrepreneurship and social businesses in India. The framework is expected to stimulate the discussions on the need and implications of reviewing existing or emerging plans for S-ENT promotion and regulation within the country. The paper out-rightly highlights the need to fill the 'policy vacuum' in S-ENT context and discusses the positive implications of policy measures at the local and state level.

While as the GOI is at nascent stage of policy development for S-ENT, the prevailing landscape is filled with abundant challenges in this direction. Thus the present research was undertaken with the aim to initiate further policy dialogues and thus to support the endeavor of a constructive S-ENT policy making in India.

For a more productive and conducive policy framework, the researchers can advance the present model by identifying and incorporating different levels of analysis, new variables as well as new sets of relationships between the system components.

\section{References}

[1]. Dees, J. G. (1994). Social enterprise: Private initiatives for the common good. Harvard Business School.

[2]. Bornstein, D. (2004). How to change the world: Social entrepreneurs and the power of new ideas. Oxford University Press.

[3]. OECD. (1999). Social Enterprises. Paris: OECD.

[4]. Social Enterprise London (2001b) Understanding Social Enterprise. London: SEL.

[5]. Young, C. (2006). Have you faced the leadership challenge?, Social Enterprise, May, 2006, Social Enterprise Coalition, London.

[6]. Smallbone, D., North, D., Roper, S., and Vickers, I. (2003). Innovation and the use of technology in manufacturing plants and SMEs: an interregional comparison. Environment and planning c, 21(1), 37-52.

[7]. Hansmann, H. B. (1980). The role of nonprofit enterprise. Yale law journal, 835-901.

[8]. Austin, J., Stevenson, H., and Wei-Skillern, J. (2006). Social and commercial entrepreneurship: same, different, or both?. Entrepreneurship theory and practice, 30(1), 1-22.

[9]. Johnson, S. (2000). Literature Review on Social Entrepreneurship, Canadian Centre for Social Entrepreneurship, Edmonton.

[10]. Nielsen, C., and Carranza, D. (2010). Knowledge Networks for Social Enterprise Success: A Systems Approach to Case Studies in Latin \{1\}America. Jacob France Institute, University of Baltimore.

[11]. Minniti, M. (2008). The role of government policy on entrepreneurial activity: productive, unproductive, or destructive?. Entrepreneurship Theory and Practice, 32(5), 779-790.

[12]. Global entrepreneurship monitor: South African executive report. Graduate School of Business, University of Cape Town, 2002.

[13]. Satar, M. S. (2015). 'Social entrepreneurship: Solution to topical problems', The Rising Kashmir, 31st Oct. 2015. Available at http://www.risingkashmir.com/news/socialentrepreneurship-solution-to-topical-problems[Accessed: October 31st 2015).

[14]. Audretsch, D. B., and Thurik, A. R. (2001). What's new about the new economy? Sources of growth in the managed and entrepreneurial economies. Industrial and corporate change, 10(1), 267-315.

[15]. Reynolds, P., Hay, M., Bygrave, W. D., Camp, S. M., and Autio, E. (2000). Global entrepreneurship monitor. Executive Report. 
[16]. Reynolds, P. D., Hay, M., and Camp, S. M. (1999). Global entrepreneurship monitor (p. 3). Kansas City, Mo.: Kauffman Center for Entrepreneurial Leadership.

[17]. Wennekers, S., and Thurik, R. (1999). Linking entrepreneurship and economic growth. Small business economics, 13(1), $27-56$.

[18]. Awasthi, D., Kashyap, S.P., and Yagnik, J. (2006). Entrepreneurial manifestations: Present trend and changing landscape in an inter-regional context, unpublished report, New Delhi, Government of India, Ministry of Micro, and Small and Medium Enterprises. Figini, P., and Santarelli, E. (2006). Openness, economic reforms, and poverty: Globalization in developing countries. The Journal of Developing Areas, 39(2), 129-151.

[19]. European Commission. Directorate-General for Regional Policy, and Cohesion. (1998). Economic and social cohesion in the European Union: the impact of Member States' own policies (Vol. 29).

[20]. Verheul, I., Wennekers, S., Audretsch, D., and Thurik, R. (2001). An eclectic theory of entrepreneurship: policies, institutions and culture (No. 01-030/3). Tinbergen Institute Discussion Paper.

[21]. Nisa, S., \& Ravichandran, N. (2013). Trade Policies and Their Impact on Business Models: A Comparative Study. IUP Journal of Business Strategy, 10(1), 20.

[22]. Noya, A., and Clarence, E. (2007). The social economy: building inclusive economies. Publications de l'OCDE.

[23]. CIRIEC (2012), The Social economy in the European Union, N . CESE/contract CES 18.106 - 2012, The European Economic and Social Committee (EESC).

[24]. Leviner, N., Crutchfield, L. R., and Wells, D. (2007). Understanding the impact of social entrepreneurs: Ashoka's answer to the challenge of measuring effectiveness. Research on Social Entrepreneurship and Contributing to an Emerging Field, 89-103.

[25]. Ireland, R. D., Hitt, M. A., Camp, S. M., and Sexton, D. L. (2001). Integrating entrepreneurship and strategic management actions to create firm wealth. The Academy of Management Executive, 15(1), 49-63.

[26]. ECOTEC. (2001). External evaluation of the Third System and Employment Pilot Action, Ecotec Research and Consulting Limited, Final Report, August. Referred to in OECD 2003.

[27]. Karnani, A. (2007). Fortune at the Bottom of the Pyramid: A Mirage, How the Private Sector Can Help Alleviate Poverty, Stephen M. Ross School of Business at the University of Michigan Working Paper. the California Management Review, 1-42.

[28]. Oatley, N. (1999). Developing the social economy. Local Economy, 13(4), 339-345.

[29]. Leadbetter, C. (1997) The rise of social entrepreneurship. London: Demos

[30]. Amin, A. (2005). Local community on trial. Economy and society, 34(4), 612-633.

[31]. Peredo, A. M., and McLean, M. (2006). Social entrepreneurship: A critical review of the concept. Journal of world business, 41(1), 56-65.

[32]. Alvord, S. H., Brown, L. D., and Letts, C. W. (2004). Social entrepreneurship and societal transformation an exploratory study. The journal of applied behavioral science, 40(3), 260-282.

[33]. Dees, J. G., and Elias, J. (1998). The challenges of combining social and commercial enterprise. Business Ethics Quarterly, 8(1), $165-178$.

[34]. OECD. (2013). European Commission, Policy Brief on Social Entrepreneurship: Entrepreneurial Activities in Europe (2013), http://www.oecd.org/cfe/leed/Social\%20entrepreneurship\%20policy\%20brief\%20EN_FINAL.pdf

[35]. Mendell, M., Pestoff, V., Noya, A., and Clarence, E. (2009). Improving Social Inclusion at the Local Level Through the Social Economy: Report for Poland.

[36]. Askoha/McKinsey and Company (2012), Etude d'évaluation de l'impact de l'entreprenariat social (unpublished).

[37]. Carree, M. A., and Thurik, A. R. (2003). The impact of entrepreneurship on economic growth. In Handbook of entrepreneurship research (pp. 437-471). Springer US.

[38]. Government of India (GOI), e Planning Commission, 2011 b): e Planning Commission Approach to the Twelve Year Plan, Technology and Innovation: http://12thplan.gov.in/12fyp_docs/13.pdf

[39]. GOI, Planning Commission 2103 http://planningcommissionplan/pdf/12fyp_vol1.pdf

[40]. GIZ (2012). Enablers for Change -A Market Landscape of the Indian Social Enterprise Ecosystem, September 2012, Prepared for GIZ by Ernst and Young Pvt. Ltd. https://www.giz.de/en/.../giz2012-enablers-for-change-india-en.pdf

[41]. Asian Development Bank, ADB. (2012). India social enterprise landscape report, Mandaluyong City, Philippines: ADB publications. http://adb.org/sites/default/.../2012/india-social-enterprise-landscape-report.pdf

[42]. Allen, S., Bhatt, A., Ganesh, U., and Kulkarni, N. K. (2012). On the Path to Sustainability and Scale: A Study of India's Social Enterprise Landscape.

[43]. Granados, M. L., Hlupic, V., Coakes, E., and Mohamed, S. (2011). Social enterprise and social entrepreneurship research and theory: A bibliometric analysis from 1991 to 2010. Social Enterprise Journal, 7(3), 198-218.

[44]. Satar, M. S., John, S., and Siraj, S. (2016). Use of marketing in social enterprises. International Journal of Social Entrepreneurship and Innovation, 4(1), 16-24.

[45]. Dees, J. (1998). Enterprising Non-profits. Harvard Business Review, 76(1), 54--67.

[46]. Mair, J., and Marti, I. (2006). Social entrepreneurship research: A source of explanation, prediction, and delight. Journal of world business, 41(1), 36-44

[47]. Storey, D. J. (1994). Understanding the small business sector. Cengage Learning EMEA.

[48]. Storey, D. J. (1999). Six steps to heaven: evaluating the impact of public policies to support small businesses in developed economies. Centre for Small and Medium Sized Enterprises, Warwick Business School.

[49]. Rotter, J. B. (1966). Generalized expectancies for internal versus external control of reinforcement. Psychological monographs: General and applied, 80(1), 1.

[50]. McClelland, D.C. (1961). The Achieving Society. New York and London: Collier Macmillan.

[51]. Harding, R. (2004). Social enterprise: the new economic engine?. Business Strategy Review, 15(4), 39-43.

[52]. Conway, C. (2008). Business planning training for social enterprise. Social Enterprise Journal, 4(1), 57-73.

[53]. Dana, L. P. (2000). Creating entrepreneurs in India. Journal of Small Business Management, $38(1), 86$.

[54]. Burns, P. (2010). Entrepreneurship and small business. Palgrave Macmillan.

[55]. Seanor, P., Bull, M., and Ridley-Duff, R. (2007). Mapping social enterprise: do social enterprise actors draw straight lines or circles?.

[56]. GOI. (2015). National Skill Development and Entrepreneurship policy of 2015 www.skilldevelopment.gov.in/National-Policy2015.html

[57]. Peredo, A. M., and McLean, M. (2006). Social entrepreneurship: A critical review of the concept. Journal of world business, 41(1), 56-65.

[58]. Alex, N. (2006). Social Entrepreneurship: New Models of sustainable social change. Oxford University Press. 
[59]. Short, J.C., Moss, W.T. and Lumpkin, G.T. (2009), "Research in social entrepreneurship: past contributions and future opportunities", Strategic Entrepreneurship Journal, Vol. 3, No. 2, p. 161-194.

[60]. Hill, J. (2000). A multidimensional study of the key determinants of effective SME marketing activity: Part 2. International Journal of Entrepreneurial Behaviour and Research, 7(6), 211-35.

[61]. Certo, S. T., and Miller, T.(2008). Social entrepreneurship: Key issues and concepts. Business horizons, 51(4), $267-271$.

[62]. Stevenson, L., and Lundström, A. (2001). Patterns and trends in entrepreneurship/SME policy and practice in ten economies (Vol. 3). Elanders Gotab:Stockholm, Sweden

[63]. Lundstrom, A., and Stevenson, L. A. (2005). Entrepreneurship policy: Theory and practice (Vol. 9). Springer Science and Business Media.

[64]. Dutz, M. A., Ordover, J. A., and Willig, R. D. (2000). Entrepreneurship, access policy and economic development: lessons from industrial organization. European Economic Review, 44(4), 739-747.

[65]. Kim, Y, W. Kim and T. Yang, 2010. The effect of public policy on entrepreneurial activity: Evidence from oECD countries. http://s baer. uca.edu/res earch/icsb/201 OlPolicy131-The\%20Effect\%20of. pdf .

[66]. Dana, L. P. (1992). A framework for the classification of government policy on entrepreneurship: contrasting six models. Journal of Small Business and Entrepreneurship, 10(1), 2-12.

[67]. Dana, L. P. (1995). Public policy and entrepreneurship in the Caribbean: nine styles of policy. J. Private Enterp, 10, 119-141.

[68]. Satar, M. S., and John, S. (2016). A conceptual model of critical success factors for Indian social enterprises. World Journal of Entrepreneurship, Management and Sustainable Development, 12(2).

[69]. Kantis, H., Ishida, M., and Komori, M. (2002). Entrepreneurship in emerging economies: The creation and development of new firms in Latin America and East Asia. Inter-American Development Bank.

Websites:

[1]. National Innovation Foundation - India at: www.nif.org.in (accessed 15th September 2015).

[2]. Planning Commission of India-GOI at: http://planningcommission.gov.in (accessed 12th August 2015).

[3]. Ministry of Skill Development and Entrepreneurship - India at: http://www.skilldevelopment.gov.in (accessed 3rd June 2015)

[4]. Ministry of Micro, Small and Medium Enterprises - India at http://msme.gov.in (accessed 12th September 2015)

[5]. The Business School of the World, INSEAD- at http://www.insead.edu (accessed 15th November 2015)

Notes

[1]. GOI is used as abbreviations of Government of India throughout this document for reasons of space.

[2]. S-ENT is used as abbreviations of social entrepreneurship throughout this document for reasons of space.

[3]. SEs is used as abbreviations of social enterprises throughout this document for reasons of space. 